Sechs neue nordamerikanische Elateriden.

Von

\title{
Otto Schwarz.
}

\section{Drasterius brevipennis.}

Rufo-testaceus, sat dense favo-pilosulus; fronte convexa, nigra; prothorace latitudine distincte longiore lateribus subrotundato, sat dense fortiterque punctato, vitta dorsali fusiformi nigra, angulis posticis sat elongatis, acutis, haud vel subdivaricatis, extrorsum carinatis; scutello convexo; elytris prothorace haud latioribus, brevibus, sutura antice, macula oblonga ante medium, plus minusve obsoleta, plagaque communi lobata postica nigris, punctato-striatis, interstitiis convexiusculis; corpore subtus rufo-testaceo, pedibus

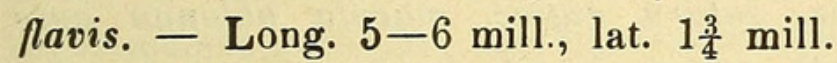

Var.: Prothoracis macula dorsali lata lateraque anguste nigra, corpus subtus nigrum: nigriventris.

Alabama.

In der Färbung veränderlich und dem dorsalis Say sebr ähnlich. Röthlich, ziemlich dicht gelb behaart. Die Stirn ist meist schwarz, zuweilen bräunlich schwarz oder braun, gewölbt, und wie das Halsschild mäfsig dicht und ziemlich stark punktirt. Die Fühler erreichen die Basis des Hlssch. Das Halsschild ist deutlich länger als breit, an den Seiten gerade und parallel, an der Spitze schwach gerundet verengt, zuweilen auch vor den langen, gerade nach hinten gerichteten, nahe dem Aufsenrande gekielten Hinterecken sehr schwach etwas ausgeschweift, mit einer spindelförmigen, schwarzen, zuweilen fast erloschenen Längsbinde in der Mitte. Die Flgd. sind an den Schultern etwas schmaler als das Hlssch. und nur $1 \frac{1}{2} \mathrm{mal}$ so lang als Kopf und Halssch. zusammen, an den Seiten leicht gerundet und hinten gerundet verengt, beiderseits vor der Mitte mit einer länglichen, schwarzen oder bräunlichen, zuweilen fast ganz erloschenen Makel und vor der Spitze mit einem gemeinschaftlichen, fünflappigen, zickzackartigen, mehr oder weniger schwarzen Fleck, das Schildchen und meist auch die Naht an der Basis dunkler, scharf punktirt-gestreift, mit schwach gewölbten, mälsig dicht und fein punktulirten Zwischenräumen. Die Unterseite ist einfarbig gelblich roth, das Abdomen zuweilen bräunlich, die Beine etwas heller gelb. 
Von 11 mir vorliegenden Ex. sind zwei vorherrschend schwarz gefärbt; das Halsschild ist schwarz und beiderseits neben dem Seitenrande nur eine schmale, nach der Basis zu etwas breitere Längsbinde roth, die vordere Dorsalmakel der Fld. ist mit dem Fleck vor der Spitze fast vereinigt; die Unterreite ist schwarz, nur die Hinterecken des Halsschildes und das letzte Abdominalsegment an der Spitze heller braun.

Diese Art ist constant kleiner als dorsalis Say, das Halsschild verhältnifsmäfsig länger, die Fld. kürzer und an den Seiten gerundet.

\section{Drasterius minor.}

Flavus, dense flavo-pubescens; fronte nigra, convexa, sat fortiter punctata; prothorace latitudine parum longiore, lateribus late subrotundato, a medio parum angustato, vitta media fusiformi nigra, sat fortiter punclato, angulis posticis haud divaricatis, extrorsum carinatis; scutello nigro; elytris prothoracis latitudine, parallelis, apice rotundatim attenuatis, sutura antice, macula oblonga ante medium plagaque lata lobata communi ante apicem nigris ornatis, striatis, striis fortiter punctatis, interstitiis convexis, parce punctulatis; corpore subtus pedibusque flavis, metathorace nigro, abdomine brunnescenti. - Long. $4 \frac{3}{4}$ mill., lat. $1 \frac{1}{4}$ mill.

\section{Alabama.}

Gelb, glänzend, fein gelb behaart. Die Stirn ist schwarz, gewölbt, dicht und mälsig stark punktirt. Die Fühler sind gelb und erreichen die Basis der Fld. Das Halsschild ist etwas länger als breit, an den Seiten nur sehr schwach gerundet und vorn nur schwach verengt, mit einer spindelförmigen, schwarzen Längsbinde, und wie die Stirn punktirt; die Hinterecken sind gerade nach hinten gerichtet und parallel dem Aufsenrande fein gekielt. Das Schildchen ist schwarz. Die Flügeldecken sind so breit wie das Halsschild, parallel, an der Spitze gerundet verengt, die Naht an der Basis, eine längliche Makel hinter der Schulter und ein gemeinschaftlicher, beiderseits bis zum Seitenrande ausgedehnter Fleck nahe vor der Spitze schwarz, ziemlich stark punktirt-gestreift, die Zwischenräume leicht gewölbt und fein, fast einreihig punktulirt. Unterseite und Beine sind gelb, Mittel- und Hinterbrust schwarz.

3. Athous exclamationis.

Fusco-niger, dense cinereo-pilosus; fronte antice truncala, medio paulo depressa, utrinque rufo-maculata, crebre sat fortiter punctata; antennis brunneis, articulo tertio secundo paulo minore; prothorace latitudine parum longiore, convexo, busi apiceque anguslato, lateribus rotundalo et postice rufo, dense sat fortiter punctato, angulis 
anticis rufis, posticis brevibus, subito divaricatis, haud carinatis; elytris prothorace parum latioribus, parallelis, apice rotundatim altenuatis, vitta sublaterali abbreviata, macula laterali ante apicem lateribusque anguste brunneo-rufis, subtiliter punctuto-striatis, interstitiis dense subtiliter rugulose punctulatis; corpore subtus nigro, pedibus rufo-testaceis, tarsorum articulo $4^{0}$ minuto. - Long. $7 \frac{1}{2}$ mill., lat. 2 mill.

Alabama.

Bräunlich schwarz, dicht und etwas abstehend gelblich grau behaart, ziemlich matt. Die Stirn ist vorn fast gerade abgestutzt, der Vorderrand in der Mitte leicht niedergedrückt, daher von oben gesehen scheinbar etwas ausgerandet, beiderseits mit einem kleinen, braunrothen Fleck. Die Fühler sind braun und erreichen nur die Basis der Fld., ihr drittes Glied ist um ein geringes kürzer und schmaler als das zweite. Das Halsschild ist ein wenig länger als breit, gewölbt, an der Basis und Spitze verengt, an den Seiten gleichmäfsig gerundet, die Vorderecken und die Seiten in den beiden letzten Dritteln mit Einschlufs der Hinterecken braunroth, Oberseite dicht und mälsig stark punktirt, die Hinterecken kurz, stark divergirend und ungekielt. Die Flgd. sind etwas breiter als das Hlssch., parallel und erst im letzten Viertel schwach gerundet verengt, eine von der Schulter bis hinter die Mitte reichende Längsbinde und ein bis zum Seitenrande ausgedehnter Fleck braunroth, Fleck und Längsbinde miteinander verbunden, die Streifen sind ziemlich fein, mälsig stark punktirt, die Zwischenräume fein punktulirt und gerunzelt, die Nabt und der äufserste Rand der Fld. ist gebräunt. Die Unterseite ist schwarz, das letzte Abdominalsegment an der Spitze braunroth, die Beine und die Epipleuren der Fld. sind bräunlich gelbroth, das zweite und dritte Tarsenglied sind nicht gelappt, das vierte aber viel kürzer und schmaler als das dritte.

Die Art ist dem vittiger Lec. verwandt, aber stärker punktirt, anders gezeichnet und in der Form des Halssch. bedeutend verschieden.

\section{Corymbites trapezicollis.}

(ठ) Nigro-fuscus, subtilissime griseo-pubescens; fronte late impressa, dense subtiliter punctata; antennis parum elongatis, serratis, articulo $3^{0} 4^{0}$ aequali, ultimo appendiculato; prothorace transverso, trapezoideo, planiusculo, dense subtiliter punctato, apice lateribusque marginato, angulis posticis divaricatis, haud carinatis; scutello rotundato, subimpresso; elytris prothorace latioribus, parallelis, apice subito rotundatis, irregulariter per partim obsolete punctato- 
substriatis, subtiliter punctulatis et rugulosis; corpore subtus pedibusque concoloribus. - Long. 21 mill., lat. 7 mill.

America borealis.

Bräunlich schwarz, mäfsig glänzend, sehr fein, wenig bemerkbar grau behaart. Die Stirn ist vorn breit und flach vertieft, fein und dicht punktirt. Die Fühler sind vom dritten Gliede an gesägt und überragen die Hinterecken des Halssch. um zwei Glieder, ihr drittes Glied ist noch etwas gröfser als das vierte, das letzte Glied ist länger als das vorletzte und vor der Spitze scharf und deutlich abgesetzt, die Fühler daher scheinbar 12 gliedrig. Das Halsschild ist deutlich breiter als lang, von der Basis an nach vorn geradlinig verengt, ziemlich flach, Seiten- und Vorderrand erhaben, sehr dicht und fein punktirt, mit der Spur einer glänzend glatten Mittellinie, die Hinterecken etwas mehr als die Halsschildseiten nach hinten divergirend, nicht gekielt. Die Flügeldecken sind breiter als das Halssch., an den Seiten gerade und parallel und erst an der Spitze fast plötzlich zugerundet, ziemlich flach, mit undeutlichen, theilweise erloschenen, nicht ganz regelmäfsigen Punktstreifen, fein punktulirt und schwach runzlig. Unterseite und Baine sind einfarbig bräunlich schwarz, das Prosternum zwischen den Vorderhüften stark gewölbt und mit feiner, erhabener Längslinie, sein Fortsatz stark nach innen geneigt; die Schenkeldecken sind in der äufseren Hälfte sehr schmal, nach innen gerundet und stark verbreitert.

Die Art gehört in die III. Section nach Candèze.

\section{Euplastius nov. gen.}

Frons antice medio deflexa, haud marginata.

Oculi prominuli.

Palpi maxillarum articulo ultimo subovali.

Antennae valde elongatae, subfiformes.

Prothorax elongatus, lateribus marginato.

Prosternum antice haud lobatum.

Suturae prosternales simplices, haud excavatae.

Laminae posticae extrorsum sensim angustatae.

Pedes graciles, tarsi simplices.

Die Stirn ist flach, vorn in der Mitte niedergebogen und nicht gerandet; die Augen sind stark gewölbt, vorragend; die Oberkiefer sind am Innenrande hinter der Spitze stumpf gezähnt.

Das letzte Glied der Kiefertaster ist etwas länger als das vorletzte, innen nach der Spitze zu schwach gerundet erweitert, in oder vor der Mitte am breitesten: 
Die Fühler sind lang und dünn, einfach, fast fadenförmig.

Die Vorderbrust ist nach vorn nicht vorragend, die Prosternalnähte sind gerade, nach hinten schwach convergirend, einfach, der ganzen Länge nach geschlossen.

Die Schenkeldecken sind nach aufsen allmählich schwach verschmälert.

Die Beine sind ziemlich schlank, die Tarsen und Klauen einfach.

Die Gattung gehört der Bildung der Vorderbrust nach zu den Campyliden und steht unter den amerikanischen Gattungen dem Aplastus Lec. wohl am nächsten, erinnert aber im Habitus mehr an Nomopleus. Von Aplastus besonders durch das lange, fast parallele, an den Seiten scharf gerandete Halssch., durch die kürzeren, stumpferen und viel weniger divergirende Hinterecken desselben, durch die längeren Fühler und die nach aufsen nur schwach und allmählich verschmälerten Schenkeldecken verschieden.

\section{Euplastius athoiformis.}

Angus/us, niger vel fuscus, dense cinereo-pilosus; fronte antice concava, creberrime umbilicalo-punctata; antennis fuscis, valde elongatis, tenuibus, articulo $3^{0} 4^{0}$ aequali; prothorace latitudine plusculus sesqui longiore, lateribus recto et marginato, a basi usque ad apicem gradatim paulo angustato, margine antica posticaque interdum linea media testaceo, creberrime fortiter rugose punctalo, canaliculato, angulis posticis favo-tesfaceis, panlo divaricatis, subtiliter carinatis; elytris prothorace parum latioribus, apice rotundatim altenuatis, testaceis, vitta dorsali lateribusque nigris, punctato-striatis, interstitiis praesertim versus basim convexiusculis, dense subrugulose punctulatis; corpore subtus nigro, abdomine pedibusque interdum plus minusve brunnescentibus. - Long. $6 \frac{1}{4}-8$ mill., lat. $1 \frac{1}{2}-2$ mill.

\section{Alabama.}

Schmal, schwarz oder bräunlich schwarz, dicht grau behaart, wenig glänzend. Die Stirn ist vorn flach ausgehöhlt, ungerandet und überall sehr dicht mit flachen, nabeligen Punkten besetzt; die Augen sind stark gewölbt, vorragend. Die Fühler sind schwärzlich, dünn und fast fadenförmig, länger als der halbe Körper, ihr drittes Glied so lang wie das vierte. Das Halsschild ist mehr als um die Hälfte länger als breit, von der Basis an nach vorn geradlinig sehr schwach verengt, an den Seiten gerandet, der Vorderrand, die Hinterecken oder auch der ganze Basalrand, zuweilen auch längs der Mitte verwaschen braun oder gelblich, mit flachen, nabeligen Punkten sehr dicht besetzt und der Länge nach gefurcht, die Längsfurche nach vorn und nach der Basis zu meist etwas schwächer 
als in der Mitte, die Hinterecken sind in der Richtung der Halsschildseiten divergirend, fein und undeutlich gekielt. Die Flügeldecken sind ein wenig breiter als das Halsschild, parallel und erst an der Spitze gerundet verengt, röthlich gelb, beiderseits neben der Naht und dem Seitenrande geschwärzt, die schwarze Rückenfärbung vorn schräg nach aufsen gerichtet und meist nahe hinter der Schulter mit der schwarzen Seitenbinde vereinigt; die Punktstreifen sind mäfsig stark, die $Z$ wischenräume nach der Basis hin leicht gewölbt, fein punktulirt und schwach gerunzelt. Unterseite und Beine sind schwarz oder zuweilen theilweise verwaschen gebräunt.

\section{Euplastius athoides.}

Fuscus, dense cinereo-pilosus; fronle antice depressa, dense punctala; antennis elongatis, articulo $3^{0} 2^{0}$ fere duplo longiore, $2-3$ conjunctim $4^{0}$ subaequalibus; prolhorace latitudine plusculus sesqui longiore, lateribus recto, subparallelo, marginato, apice solum paulo rotundatim angustato, haud vel basi obsolete canaliculato, creberrime punctato, angulis posticis flavo-testaceis, subdivaricatis, obtuse carinatis; elytris prothorace sublatioribus, subparallelis, apice rotundatim attenuatis, vitta sublaterali plagaque basali flavo testaceis, sat fortiter punctato-striatis, interstitiis convexiusculis, subtiliter rugulosis; corpore sublus fusco, pedibus brunneis. - Long. 8 mill., lat. 2 mill.

California.

Schwärzlich braun, fein und dicht gelblich grau behaart, matt. Die Stirn ist vorn nur flach eingedrückt, dicht nabelig punktirt. Die Fühler sind kräftiger als bei der vorigen Art und reichen bis zu den Hinterhüften, ihr drittes Glied ist fast doppelt so lang.wie das zweite und beide zusammen kaum länger als das vierte. Das Halsschild ist mehr als $1 \frac{1}{2} \mathrm{mal}$ so lang wie breit, an den Seiten gerade und fast parallel, gewölbt, sehr dicht und etwas runzelig punktirt, die Punkte nicht deutlich genabelt, obne Mittelfurche, die Hinterecken sind gelb, schwach divergirend, stumpf und undeutlich gekielt. Die Fld. sind reichlich so breit wie das Hassch. und erst an der Spitze gerundet rerengt, dunkel braun; ein kleiner, nach hinten verwaschen begrenzter Basalfleck und eine Längsbinde nahe dem Seitenrande ebenfalls nicht scharf begrenzt gelb; die ziemlich tiefen Streifen sind stark punktirt, an der Spitze schwächer, die Zwischenräume gewölbt und fein runzlig, ohne deutliche Punkte. Die Unterseite ist bräunlich schwarz, die Beine und Epipleuren der Fld. sind heller braun. - Durch Hrn. Oberndorffer erhalten. 


\section{$2 \mathrm{BHL}$ Biodiversity Heritage Library}

Sohwere, Otto. 1903. "Sechs neue nordamerikanische Elateriden." Deutsche entomologische Zeitschrift 1903(1), 57-62. https://doi.org/10.1002/mmnd.48019030106.

View This Item Online: https://www.biodiversitylibrary.org/item/103315

DOI: https://doi.org/10.1002/mmnd.48019030106

Permalink: https://www.biodiversitylibrary.org/partpdf/235810

\section{Holding Institution}

Harvard University, Museum of Comparative Zoology, Ernst Mayr Library

\section{Sponsored by}

Harvard University, Museum of Comparative Zoology, Ernst Mayr Library

\section{Copyright \& Reuse}

Copyright Status: Public domain. The BHL considers that this work is no longer under copyright protection.

This document was created from content at the Biodiversity Heritage Library, the world's largest open access digital library for biodiversity literature and archives. Visit BHL at https://www.biodiversitylibrary.org. 